\author{
Mehrab Dashtdar ${ }^{1}$, Mohammad Reza Dashtdar², Negar Taheri ${ }^{3}$, Babak Dashtdar ${ }^{4}$ \\ ${ }^{1}$ Department of Integrative Medicine, Dubai Specialized Medical Centre \& Medical Research Lab, Dubai Medical College and Dubai Phar- \\ macy College, Dubai, United Arab Emirates \\ ${ }^{2} \mathrm{~A} \& \mathrm{E}$, London, United Kingdom \\ ${ }^{3}$ Department of Pathology, School of Medicine, Shiraz University of Medical Sciences, Shiraz, Iran \\ ${ }^{4}$ Shiraz University of Medical Sciences, Shiraz, Iran
}

\title{
Rationale and design of a clinical trial to evaluate the safety and efficacy of gum Arabic in patients with nephrolithiasis and renal cyst simultaneously
}

\section{Corresponding author:}

Mehrab Dashtdar, Department of Integrative Medicine, Dubai Specialized Medical Centre \& Medical Research Lab, Dubai Medical College and Dubai Pharmacy College, Dubai, United Arab Emirates, e-mail:dr.mehrab@gmail.com

Medical Research Journal 2021; Volume 6, Number 3, 184-193 10.5603/MRJ.a2021.0034 Copyright (C) 2021 Via Medica ISSN 2451-2591 e-ISSN 2451-4101

\begin{abstract}
The elderly group is one of the most heterogeneous and vulnerable groups of the population in developed countries with a greater risk of suffering from imbalances, deficiencies and nutritional problems. Diet and nutritional status have a great influence particularly on the prevention or treatment of various diseases that affect these groups. Long-term accumulation of waste in the body and age-related changes in metabolism create many problems that shorten their life expectancy. Their diet and gastrointestinal function play a key role in their Urine composition. It seems that the gastrointestinal microbiome has a great influence on the metabolization and absorption of the ingredients of the diet. In this clinical trial, the authors concluded that oral administration of gum arabic dissolved in orange juice could conceivably wash out the renal stones and eliminate renal cysts which in the long-term did not raise any safety concerns. The oral administration of gum arabic reduces kidney failure and slows its progression, which might be ascribed to their antioxidant and free radical-scavenging properties. Gum arabic could be considered as an important natural medicinal compound, actually a fascinating one because of its high therapeutic capabilities. Therefore, a prospective observational study has been designed and aimed to assess the efficacy and safety of treatment with gum arabic in patients with nephrolithiasis and renal cysts. Key words: gum arabic, prebiotic, orange juice, kidney cysts, renal lithiasis, chronic kidney disease
\end{abstract}

Med Res J 2021; 6 (3): 184-193

\section{Introduction}

Kidney cysts and stones when occurring in the elderly are risk factors for developing chronic kidney disease (CKD), which is seen globally. CKD recorded a global prevalence of $9.1 \%$, which is more prevalent in men, in elderly subjects, and subjects with CVD or cardiovascular risk factors. The prevalence of kidney stones and cysts among chronic kidney disease patients is $11.2 \%$ and $10.7 \%$ respectively.

\section{Kidney cystic diseases}

The kidney is one of the places in the body where cysts develop frequently [1]. In 1988, Gardner suggest- ed that a tubular dilation four times the normal diameter (more than $200 \mu \mathrm{m}$ ) should be called a cyst. Cystic kidney disease is often discovered either during the workup for kidney failure through ultrasound, or incidentally during an imaging test or family investigation. The most common forms of kidney cysts are simple cysts and acquired cystic disease (usually associated with dialysis). In general, the association with symptoms has been considered a mere coincidence. They can be detected by ultrasound and radiological studies indicated for urological problems, arterial hypertension or haematuria. In 1930, Hepler proposed that its aetiology could be a tubular obstruction, which distends and become cystic due to the continuous flow of urine, however, this is not the only mechanism involved in its formation [2].

This article is available in open access under Creative Common Attribution-Non-Commercial-No Derivatives 4.0 International (CC BY-NC-ND 4.0) license, allowing to download articles and share them with others as long as they credit the authors and the publisher, but without permission to change them in any way or use them commercially. 
Some fundamental aspects for its development have been also mentioned: 1) abnormal proliferation and/or lack of differentiation of renal epithelial cells; 2) continuous flow of fluid (urine); 3) Abnormalities in the tubular basement membrane and/or extracellular matrix [3].

The other proposed mechanism is chronic hypokalaemia, which has been described as causing structural and functional abnormalities including increased renal cell growth [4], renal condensing capacity, interstitial fibrosis, chronic inflammation, and defects [5]. This type of cyst formation has been reported in primary hyperaldosteronism [6, 7], distal renal tubular acidosis (dRTA) $[8,9]$, Bartter's syndrome [10, 11] and in apparent mineralocorticoid excess syndrome [12]. Meanwhile, acquired renal cysts are observed in chronic kidney disease [13]. A renal cyst is a cavity filled with fluid, limited by a single layer of epithelial cells (may be cuboidal or flattened), the origin of which is a dilation of any part of the nephron or the collecting tubule. The presence of cysts in the kidneys is a common occurrence and its incidence increases with age. In the autopsy series, more than $50 \%$ of subjects 50 years of age present at least one microscopic renal cyst. The alteration of the structure and function of the primary cilia appears to be a common factor in the pathogenesis of renal cystic diseases.

\section{Simple cyst}

Simple, solitary, or multiple kidney cysts are usually harmless and detected incidentally. They are common cystic lesions in adulthood. They are located in the cortex, are usually unilateral and their highest incidence is observed after 40 years of age $[14,15]$. They have a predilection for the male sex (M:F - 2:1), the left kidney and the upper renal pole [16]. However, they are rare in infants and children, where they usually appear as solitary lesions. Sonographically, they appear in the renal cortex, they are usually less than $1 \mathrm{~cm}$ in diameter thin-walled, predominantly unilocular and without echo-refringence in their interior $[17,18]$. They are not hereditary, but little is known about the contribution of genetic and environmental factors to their formation. In the natural history of simple kidney cysts, they can be a few millimetres or several centimetres in diameter (their size ranges are between $<0.1$ to $>10 \mathrm{~cm}$ ), which sometimes increase in size over time. Microscopically, a single layer of cuboidal or flattened cells surrounded by dense fibrous tissue lines cyst. In computerized axial tomography, the characteristic of a simple cyst is clearly separated from the surrounding parenchyma, it has a thin and smooth wall, the cyst fluid is homogeneous, with a density similar to water, and there is no evidence of intensification of the cyst mass after contrast administration [19].

\section{Renal lithiasis}

Urate stones have particularly been shown to be associated with diabetes, cardiovascular disease, hypertension, and chronic kidney disease [20]. Some studies show that simple renal cysts are a tubular development anomaly rather than an acquired secondary lesion. They hypothesise that both entities, renal cysts, and genetic predisposition to kidney stones, are related. Since simple renal cysts are assumed to be acquired, a possible first causal mechanism would be mechanical, that is; the cyst would occur secondary to an intratubular obstruction, caused by crystalluria in the other word kidney stones could be a risk factor in the presence of simple renal cysts [21]. Previous studies show that gum arabic can reduce serum uric acid levels and reverse the process of kidney failure. However, the radical treatment of simple kidney cysts with gum arabic has not been investigated.

\section{Role of diet in influencing the urine composition}

Key urinary parameters that might be affected by the microbiome include oxalate and citrate. The intestinal microbiome contains numerous obligate and generalized oxalate degrading bacteria. Evidence advises that the faecal content of Oxalobacter formigenes, the best-studied oxalate degrader, vary and is linked to stone formation risk and urinary oxalate excretion. To date, all attempts to destroy oxalate by probiotics, including those containing Oxalobacter, Lactobacillus, and/or Bifidobacterium spp. have been disappointing. From this study, it was concluded that oral administration of gum arabic dissolved in orange juice could conceivably wash out the renal stones and eliminate renal cysts. The oral administration of gum arabic reduces kidney failure and slows its progression, which might be ascribed to their antioxidant and free radical-scavenging properties.

\section{What is gum arabic?}

Naturally, gum arabic (GA) is white-yellow to brownish-yellow colour crystal shape. To use in the food and pharmaceutical industries, after collecting the exudates, grinding and purification by dissolution in the water, pasteurization and ultrafiltration, and dried by spray drying and is packed as a form of pre-hydrated powder. The product obtained is non-toxic, easily soluble in water, colourless, does not have a strong taste and odour and, above all, does not distort the taste and odour of the food system. Gum arabic is a unique polysaccharide, which has excellent emulsifying properties and, despite its relatively high molecular weight $(460,000)$, forms solutions of surprisingly low viscosity, 
has a bland taste and is odourless best tolerated by the intestine and its metabolism by bacteria is gentle and progressive. Even at high doses, it does not produce bloating or fermentation. This fibre also has a regulatory action on the water content of the stool, favourably influencing the regularity of intestinal transit. Gum arabic is widely used in various fields of the food industry as an effective stabilizer of disperse systems, structure and texture control of foods, a film-forming agent, a material for microencapsulation etc. These functional properties exist thanks to the characteristics of gum arabic chemical structure. There is a great deal of experimental evidence that insufficient intake of dietary fibre in the diet by humans leads to a high risk of diabetes, obesity, hypertension, digestive tract, cardiovascular system, renal and others disease. Conversely, a large number of clinical data confirm that the consumption of dietary fibre protects against these diseases. In addition, according to strictly confirmed epidemiological data, clinical and research evidence on the physiology of dietary fibre intake improves gastrointestinal function, glucose homeostasis and serous exudate lipid content $[22,23]$. It has antioxidant and anti-inflammatory properties used in the treatment of various kidney, cardiovascular and gastrointestinal diseases [24]. Used as an emulsifier and stabilizer in the food and pharmaceutical industries. As a "dietary fibre", gum arabic contains various carbohydrates such as I-arabinose, I-rhamnose, and d-glucuronic acid. The backbone structure of gum arabic is mainly composed of 1 , 3-linked $\beta$-d-galactopyranosyl units which resist hydrolysis by human digestive enzymes, but can be fermented by the colonic microflora, cause a greater increase in bifidobacteria and lactobacilli and mostly excreted in the faeces. The GA solutions contained particularly high concentrations of $\mathrm{Ca}_{2}{ }^{+}, \mathrm{Mg}_{2}{ }^{+}$, and $\mathrm{K}^{+}$. Because of enhanced uptake, treatment with $\mathrm{GA}$ significantly increased both the intestinal and renal excretion of $\mathrm{Mg}_{2}{ }^{+}$and $\mathrm{Ca}\left(2^{+}\right)$. The latter was accompanied by decreased urinary excretion of inorganic phosphate and decreased plasma concentrations of 1.25 dihydroxy vitamin $\mathrm{D}\left(1.25(\mathrm{OH})_{2} \mathrm{D}\right)$. Moreover, GA significantly increased faecal weight and $\mathrm{Na}^{+}$ excretion [25].

\section{Health benefits of gum arabic or acacia gum}

While gum arabic has been extensively investigated for its properties as a hydrocolloid with various food applications, it has also been the subject of more recent research for its ability to improve human health. Because gum arabic can reach the large intestine and resist digestion in the small intestine, it can be classified as an indigestible carbohydrate or dietary fibre. Gum arabic can also be classified as a prebiotic. In the large intestine, gum arabic is fermented by bacteria that produce short-chain fatty acids (SCFA), particularly propionic acid, as by-products of fermentation that are associated with significant improvements to human health [26].

\section{Bifidogenic}

Fermentation of gum arabic has been shown to selectively increase the proportions of lactic acid-producing bacteria and bifidobacteria in study subjects. It also increases the water content of the stool and increases the production of stool.

Gum Arabic is known to feed several different strains of indigenous bifidobacteria, including B. longum [27], and was shown to increase Bifidobacterium animalis subsp. lactis BB-12 ${ }^{\circledR}$ significantly better than inulin and glucose [28].

\section{Prebiotic}

Gum arabic can selectively increase the proportions of lactic acid bacteria and bifidobacteria in healthy subjects. It ferments slowly, with digestibility of around 95\%. Gum arabic also increases stool production by increasing the water content of the stool. It is well tolerated in high daily doses and is consumed without any adverse intestinal events. Evidence shows that acacia gum acts as a prebiotic at a dose of $10 \mathrm{~g} /$ day [29].

\section{Short-chain fatty acids (SCFAs)}

Other research has shown that bacterial fermentation with gum arabic produced more SCFAs such as butyrate and propionate in vitro and in vivo than other well-known prebiotics, such as pectin, inulin, and alginate. This is unequivocal evidence that gum arabic is an indigestible prebiotic polysaccharide [30].

Therefore, the simple addition of gum arabic improved food metabolically for human use. Treatment with gum arabic increased urinary $\mathrm{Ca}_{2}{ }^{+}$excretion and decreased plasma phosphate concentration and plasma urea concentration. The urinary flow rate, natriuresis, phosphaturia, glycosuria, proteinuria, and blood pressure (BP) in diabetic mice were also decreased. These results suggest that the effect of gum arabic on intestinal glucose transport may be useful in the prophylaxis and treatment of metabolic disorders such as obesity and diabetes [31].

\section{Nephroprotective}

Gum arabic increases creatinine clearance, increases renal excretion of antidiuretic hormones, decreases plasma phosphate concentration, increases renal secretion of antidiuretic hormone, and is used as a treatment for chronic kidney disease and in a terminal stage in Middle Eastern countries. Gum arabic may also serve as a treatment for kidney disease due to its ability to trap bile salts along with its relatively high effect on bu- 
tyrate production, which has been shown to suppress TGF-beta1 cytokine production [32-34].

\section{Material and methods}

The objective of the proposed clinical trial is to evaluate the benefit/tolerance ratio and to determine the optimal dosage of gum arabic in patients with nephrolithiasis. The low efficacy of available treatments for kidney stones and persistent renal cysts is the main reason for the design and conduct of this clinical trial.

\section{The study design}

This clinical trial was conducted by the medical teams of researchers in Dubai Pharmacy College with the collaboration of Shiraz University of Medical Sciences, Iran. This clinical trial launched in 2016, and proceed in 5 years (Fig. 1).

- Primary efficacy endpoint: ultrasonographic assessment of kidney stones and cysts at one year after enrolment into the study;
- Primary safety endpoint: occurrence of any side effect of evaluated treatment at one year after enrolment into the study;

- Secondary efficacy endpoint: ultrasonographic assessment of kidney stones and cysts five years after enrolment into the study;

- Secondary safety endpoint: occurrence of any side effect of evaluated treatment five years after enrolment into the study;

- Study population: adult patients (age $\geq 18$ years) with a history of nephrolithiasis and proteinuria meeting inclusion criteria.

\section{Safety variables and analysis}

Monitoring/evaluation in particular of adverse drug reactions/adverse events/toxic effects/periodical assessment on clinical laboratory parameters. Including microalbuminuria dipstick, BUN, creatinine, ALT, AST, uric acid, total bilirubin and alkaline phosphatase, by using standard forms, including symptoms, date and time of onset, first observation, diagnosis, end of episode and outcome, as recommended by the protocols

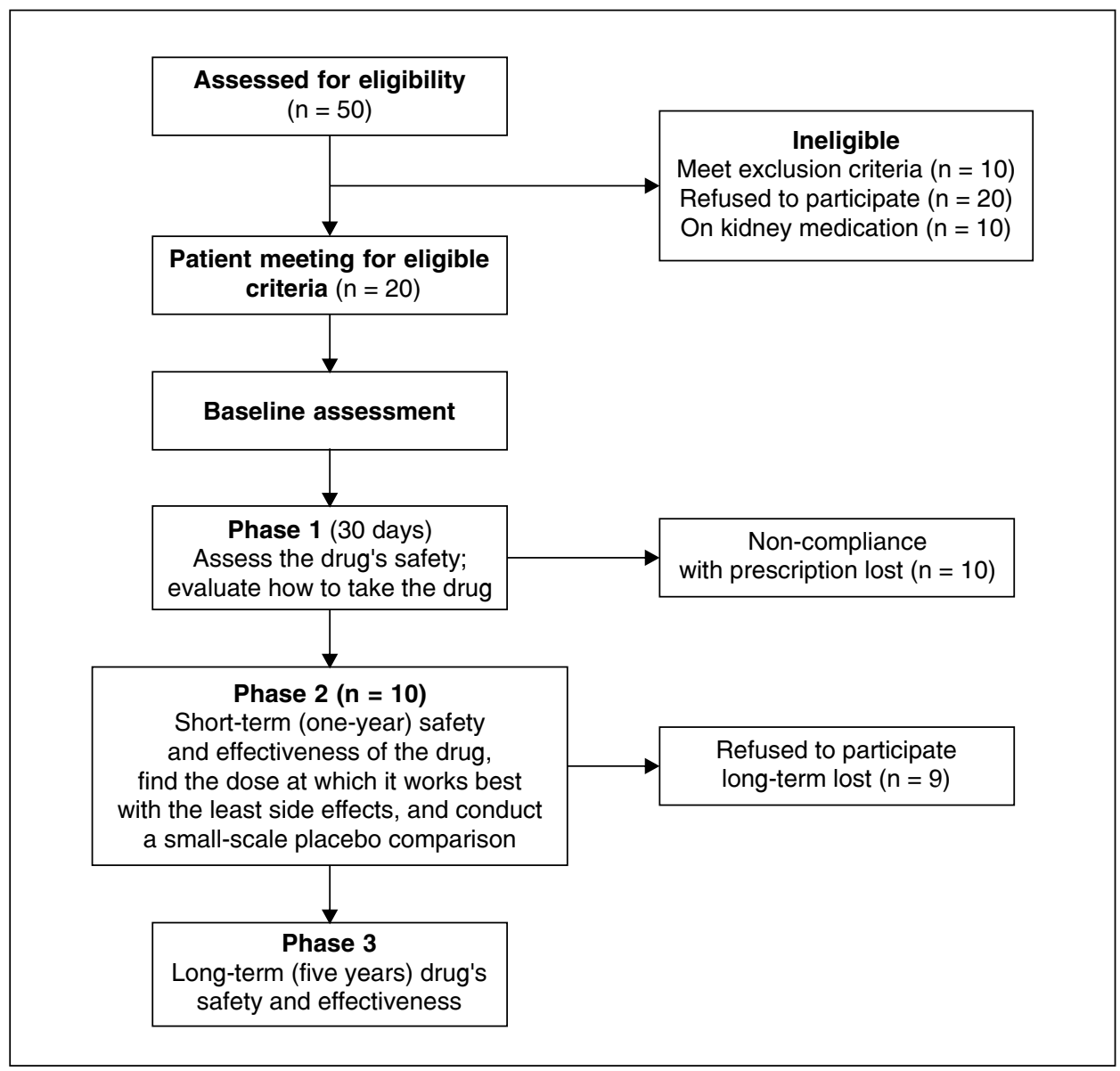

Figure 1. Clinical trial flowchart including the number of patients assessed so far 
Table 1. Urine analysis and blood biochemical parameters of the patient before and after of the gum Arabic treatment

\begin{tabular}{lccc}
\hline & $\begin{array}{c}\text { Normal range } \\
\mathbf{2 0 1 6}\end{array}$ & $\begin{array}{c}\text { Before treatment } \\
\mathbf{2 0 2 1}\end{array}$ & After treatment \\
\hline Microalbuminuria dipstick & $0-30 \mathrm{mg} / \mathrm{dL}$ & $10-300 \mathrm{mg} / \mathrm{dL}$ & 0 \\
BUN & $7-20 \mathrm{mg} / \mathrm{dL}$ & 18.1 & 19 \\
Creatinine & $0.74-1.35 \mathrm{mg} / \mathrm{dL}$ & 0.98 & $1 \mathrm{mg} / \mathrm{dL}$ \\
ALT & $29-33 \mathrm{IU} / \mathrm{L}$ & 18 & 20 \\
AST & $5-40 \mathrm{U} / \mathrm{L}$ & 14 & 16 \\
Uric acid & $4.0-8.5 \mathrm{mg} / \mathrm{dL}$ & 8.6 & 3.4 \\
Bilirubin total & $1.2 \mathrm{mg} / \mathrm{dL}$ & 1 & 0.4 \\
Alkaline phosphatase & $44-147 \mathrm{IU} / \mathrm{L}$ & 74 & 68
\end{tabular}

BUN — blood urea nitrogen; ALT — alanine aminotransferase; AST — aspartate aminotransferase

on safety, efficacy, standardization, and documentation

of herbal medicine (IUPAC technical report).

Inclusion criteria for gum arabic hypothesis:

- Adult patients (age $\geq 18$ years);

- History of nephrolithiasis and proteinuria;

- Willing to participate in the study and provide informed consent;

- Not enrolled in another trial;

- Estimated survival of at least 5 years.

Exclusion criteria for gum arabic hypothesis:

- Known major complicated disease;

- Haemodialysis patients or severe renal insufficiency defined as $\mathrm{CrCl}<30 \mathrm{~mL} / \mathrm{min}$ );

- Lack or withdrawal of informed consent;

- Not adhering to this study prescriptions;

- Any allergic reaction to gum arabic;

- Use of other medication for renal disease.

\section{Pharmaceutical formulation}

A total of 15 grams of acacia Senegal powder dissolved in $250 \mathrm{~mL}$ fresh orange juice had it with breakfast daily. For the first 3 months, it was used to add in milk then changed to fresh orange juice.

\section{Preliminary results - case report}

At the end of phase three, long-term (five years), in on an abdominal ultrasound examination, it was found that the patient's chronic cyst and kidney stone have disappeared. The $10 \mathrm{~mm}$ kidney cyst in the renal cortex was discovered incidentally during a training check-up in 1990. It persisted until 2015 without changing in size. Since 1990 , now and again he has suffered from kidney stones and proteinuria $(+$ to +++ ) frequently. An abdominal ultrasonography scan in December 2020 unexpectedly showed that there was no trace of kidney cyst or stone.

Our results showed that the renal cyst and stone were completely disappeared simultaneously. It was found to be a safe, effective, and economic method for the treatment of renal cysts and stones. The test results in Table 1 show that gum arabic has no side effects for long-term consumption.

\section{Discussion}

Chronic kidney disease (CKD) is a pathology of various origins affecting kidney function. One strategy to prevent the progression of CKD is to decrease the uremic retention molecules (URMs) using prebiotics. This study aimed to evaluate the administration of gum arabic dissolved in fresh orange juice for the elimination of kidney cysts and stones hence the potential of reducing the progression of CKD. Factors such as hypercalciuria (resorptive, renal leak, absorptive, and metabolic diseases), hyperuricosuria, Oxidative stress, excessive protein intake, hyper-oxaluria, hypo-citraturia, hypo-magnesuria, and hyper-cystinuria, contribute to kidney stone and cyst formation [35-37].

\section{Changes in urinary $\mathrm{pH}$ and Proteinuria}

The study reported that both entities, kidney cysts and genetic predisposition to kidney stones, are related [38-41]. Excessive protein intake increases the urinary excretion of uric acid, calcium, oxalate, and decreases urinary $\mathrm{pH}$ and citric excretion. Uric acid crystals form at acidic $\mathrm{pH}$. Therefore, this type of crystals can form, even in the presence of normouricemia, in situations of persisting acidic urinary $\mathrm{pH}$, especially in those patients with an excess intake of proteins of animal origin. When the urinary $\mathrm{pH}$ is persistently below 5.5 , uric acid is in the undissociated and insoluble form, so it can crystallize as a pure form. A disorder, generally of familial origin, has been described, consisting of a decrease in ammonia synthesis by the renal proximal tubular cell and, consequently, decreased urinary ammonia. The deficit of this urinary buffer gives rise to an excess of free hydrogen ions in the urine that would reduce its $\mathrm{pH}$ [42]. Orange 
juice contains a series of strong antioxidants including flavonoids (hesperetin and naringenin predominantly as glycosides), carotenoids (xanthophylls, cryptoxanthins, carotenes), and ascorbic acid and additionally other beneficial phytochemicals, like folate. All of these are believed to be significant contributors to the preventive effects of orange juice in the inflammatory process, which leads to chronic kidney disease. In addition, the combination of orange juice and gum arabic leads to the production of potassium and magnesium citrate. These compounds are useful for alkalizing urine in patients prone to develop urate and cystine stones.

\section{Uric acid and NOD-LRR-and pyrin domain- containing protein 3)NLRP3 (inflammasome}

The inflammatory response makes it possible to fight against the "non-self" such as infectious organisms or exogenous particles. The inflammasome is an intracytoplasmic multi-protein complex activated by cell stresses or infections and is responsible for the release of pro-inflammatory cytokines, including IL- $1 \beta$. The NLRP3 inflammasome, the most studied of the inflammasomes, is involved in inflammatory pathologies such as Crohn's disease, rheumatoid arthritis or gouty arthritis. Uric acid is a damage-associated molecular pattern (DAMP), released from ischemic tissues and dying cells which, when crystallized, can activate the NLRP3 inflammasome, is associated with water ingress leading to cell swelling [43].

Histopathological study of atherosclerotic lesions reveals the presence of inflammatory cells (activated $T$ lymphocytes and macrophages), as well as abundant pro-inflammatory cytokines (IL-1, IL-6, IL-8, TNF- $\alpha$, INF- $\gamma$, etc.), which modulate the local inflammatory response, altering plaque stability and favouring the development of acute cardiovascular events. However, the role of anti-inflammatory cytokines has not been as well studied.IL-10 is an anti-inflammatory cytokine capable of inhibiting the synthesis of pro-inflammatory cytokines by $\mathrm{T}$ lymphocytes and macrophages, as well as other inflammatory functions of these cells [44, 45]. IL-6 is a critical point in the inflammatory cytokine network. Under conditions of autoimmunity and chronic inflammation, elevated levels of IL- 6 can affect the homeostasis of multiple physiological processes and contribute to chronic inflammation and disease progression [46-49]. IL-6 could be produced by renal resident cells, including podocytes, mesangial cells, endothelial cells, and TECs. Meantime, all these cells, as well as immune and inflammatory cells will actively respond to IL-6 via classic or/and trans-signalling pathways.

The role of albumin in the formation of kidney stones has been described, acting as a heterogeneous nucleant and favouring the crystallization of calcium oxalate and sodium urate [50-52]. A large number of patients with proteinuria showed multiple kidney cysts on ab- dominal ultrasonography. Bilateral kidney cysts were detected in $56 \%$ of patients with proteinuria, whereas no patient with negative proteinuria showed kidney cysts or other radiological abnormalities [53]. Proteinuria can cause kidney cysts by tubular obstructions, or kidney stones acting as a heterogeneous nucleant, vice versa.

Gum arabic simultaneously reduces proteinuria and serum uric acid hence motivates the elimination of renal cysts and kidney stones.

\section{Oxidative stress}

Reactive oxygen species (ROS) can damage lipids, nucleic acids, and proteins, thereby altering their functions. Oxidative stress reflects an imbalance between the systemic manifestation of reactive oxygen species and the ability of a biological system to detoxify reagent intermediates or to repair the resulting damage. Oxidative stress has been linked to the pathogenesis of a variety of diseases, including kidney and cardiovascular disease, atherosclerosis, hypertension, cancer, diabetes, arthritis, neurodegenerative diseases (i.e., Alzheimer's and Parkinson's disease), and ageing. For its elimination, the body has an antioxidant defence system made up of enzymatic elements (superoxide dismutase, glutathione peroxidase, catalase) and non-enzymatic elements (glutathione, ascorbic acid, $\alpha$-tocopherol). Oxidative stress, a situation in which there is an excess of these highly reactive molecules with oxidative capacity, has been related to important deleterious actions, such as lipid peroxidation, protein oxidation, nucleic acid damage, induction of transcription factors such as NF- $\kappa \mathrm{B}$, stimulation of cell hypertrophy and proliferation, or induction of apoptosis [54, 55]. Oxidative stress stimulates the sympathetic nervous system and increases glomerulosclerosis, renal fibrosis, and proteinuria. On the contrary, adiponectin protects the kidney by reducing podocyte dysfunction. Oxidative processes are increased in patients with renal failure and especially in patients with end-stage renal failure on dialysis. Gum arabic is said to have an antioxidant effect and this will decrease the harmful effect of free radicals in haemodialysis patients [56]. The kidney has a very important endothelial surface and recently much importance has been given to vascular damage that produces ischemia of kidney tissue and progression of chronic kidney disease. Therefore, the preservation of vascular integrity and the endothelial wall not only prevents the cardiovascular events associated with chronic kidney disease but is also a very important aspect in slowing the progression of kidney disease. The endothelial cells of the vascular tree respond to signals such as endocrine or paracrine hormones, cytokines and growth factors, exogenous and endogenous toxins, including traditional and non-traditional vascular risk factors. On the other hand, the endothe- 
lium also responds to rheological and hemodynamic changes. However, of all of them, oxidative stress and inflammation are the most important elements that produce endothelial and vascular dysfunction in patients with chronic kidney disease. Following the above, the consumption of foods rich in antioxidants will prevent the manifestation of oxidative stress and, therefore, will provide us with a good quality of life [57-59].

Several studies carried out reveal that gum arabic had nephron-protective properties, among which the authors can mention nephrotoxicity induced by gentamicin (antibiotic) and cisplatin [60] or by cardiotoxicity induced by doxorubicin, which was carried out on rats [61]. Tromer and Neubert have shown that the treatment of GA with the addition of polysaccharides decreases lipid peroxidation [62]. It is believed that the antioxidant capacity of GA may be related to its ability to bind biomolecules such as lysine, tyrosine and histidine [63]. In other studies, using GA with tap water (15\% w/v) have shown reduced plasma urea and creatinine concentrations linked to adenine-related chronic kidney disease (RCF) and a significant decrease in the negative effects induced by adenine [64]. The protective effects of GA on kidney tissue greatly reduced urea nitrogen and creatinine concentrations in patients with diabetic nephropathy [32].

\section{Serum phosphorus}

High serum phosphorus levels are strongly and independently associated with the rate of progression of renal function deterioration in patients with advanced CKD, as well as cardiovascular morbidity and mortality [65-67]. Hyperphosphatemia has been associated with increased blood pressure and hyperdynamic circulation [68]. Phosphorus overload has also been observed to damage the podocyte in experimental animals [69]. These two mechanisms could alternatively explain a causal relationship between phosphorus and the magnitude of proteinuria.

The magnitude of proteinuria and the degree of metabolic acidosis, factors that are associated with higher phosphorus concentrations, have also been implicated as determinants of the rate of progression of CKD [70, 71]. Gum arabic acts as a phosphate-binding agent is a safe treatment of hyperphosphatemia in the intestinal tract [23]. The theory of the lack of inhibitors establishes that the absence or deficiency of natural inhibitors of lithogenesis (magnesium, citrate, pyrophosphates, acid glycoproteins and some trace metals) would be responsible for the formation of kidney stones [72-76]. The magnitude of proteinuria is the main modifiable factor that decisively influences prognosis and clinical decision-making and is an independent factor for cardiovascular risk. It has a direct renal toxic effect, induces inflammation and tubule-interstitial fibrosis, and contributes to the loss of the nephron mass [77-83].

\section{Salt \& kidney stones}

Calcium excretion is directly linked to sodium excretion, i.e., sodium intake. A high salt diet is a risk factor for kidney disease, also associated with kidney stones. It can increase the amount of calcium lost in the urine, which can cause kidney stones [84-88]. Approximately, a dietary increase of $100 \mathrm{mmol}$ of sodium generates an increase in urinary calcium of one mmol. This physiologic feature does not make much difference between different races [89]. In postmenopausal women, the occurrence of kidney stones is associated with a history of hypertension and a low dietary intake of magnesium and calcium, as they increase urinary oxalate excretion [90]. Gum arabic not only increased faecal weight, compatible with the action of dietary fibres, but also it seems that it bounds free water, which results in a reduction of intestinal fluid absorption. Possibly, due to decreased intestinal water uptake, the plasma $\mathrm{Na}^{+}$concentration is increased during gum Arabic treatment. The increased extracellular $\mathrm{Na}^{+}$ concentration may have accounted for the stimulation of $A D H$ release, which is reflected by increased urinary $\mathrm{ADH}$ excretion. Consequently, the ADH stimulates renal water reabsorption, thus decreased urine volume. Gum arabic further enhances the intestinal elimination of $\mathrm{Na}^{+}$, resulting in a major reduction of renal $\mathrm{Na}^{+}$excretion. The impaired intestinal $\mathrm{Na}^{+}$absorption may be thanks to the $\mathrm{Na}^{+}$binding ability of the gum. Magnesium forms complexes with oxalate, reducing the supersaturation of calcium oxalate. Furthermore, magnesium oxalate complexes reduce the intestinal absorption of oxalate. At physiological oxalate concentrations, magnesium reduces both stone nucleation and growth rates [91]. Citrate salts therapy is available in most prescriptions for kidney stones to raise urine $\mathrm{pH}$ to an optimal level and increase urinary citrate levels. Citrate supplementation like potassium and magnesium citrate is prescribed for the patients with recurrent calcium lithiasis, uric acid and hyperuricosuria, cysteine stones, renal tubular acidosis, chronic diarrheal syndrome, essential hypocitraturia or secondary to thiazides. Hypocitraturia and hypercalciuria are entities that have been treated with potassium citrate with satisfactory results. Citrate is known to be a potent inhibitor of kidney stone formation. In the urine, several substances facilitate the formation of soluble complexes with cations and are generically known as crystallization inhibitors. The decrease or absence of these inhibitors facilitates the formation of stones. Citrate retards the crystallization of calcium salts through two mechanisms: a) it complexes with calcium and reduces the concentration of ionic calcium in the urine; b) citrate directly inhibits the crystallization of calcium oxalate and calcium phosphate. Hypocitraturia is a common finding in patients with calcium oxalate renal lithiasis. Numerous articles show that the decrease in urinary citrate in pa- 
tients with renal lithiasis varies between $19 \%$ and $63 \%$. In the Dallas study, isolated hypocitraturia was found in $5 \%$ of patients, and associated with other abnormalities in $50 \%$ of patients with lithiasis [92-95].

Potassium citrate causes a decrease in urinary calcium and the saturation of calcium oxalate; in addition, it increases the inhibitory activity against calcium oxalate crystallization, while sodium citrate does not alter urinary calcium, nor does it have any inhibitory effect on calcium oxalate or calcium phosphate crystallization [96]. However, consumption of citrate salts has many side effects, such as gastrointestinal disturbances, black or tarry stools, convulsions, severe diarrhoea, nausea, or vomiting, severe stomach pain, difficulty breathing, hyperkalaemia which may result in muscle cramps or weakness, dizziness, confusion or restlessness, bradycardia, arrhythmias, tingling of extremities and cold skin. Citrate salts are contraindicated in pregnant or breastfeeding women, bleeding disorders, kidney impairment, uncontrolled diabetes, severe cardiac disease and citrate allergy. While these problems are not found in, the consumption of gum arabic mixed in fresh orange juice. Gum arabic is a more palatable and less expensive alternative for citrate supplementation. Gum arabic plays an important antioxidant and protective role to combat many diseases such as renal, cardiovascular, gastrointestinal and respiratory diseases, due to its remarkable effect on oxidative stress and DNA damage. Study shows that gum arabic has a powerful immunomodulatory effect. Patient safety is a discipline of health care that emerged with the evolution of the complexity of health care systems and the consequent increase in harm to patients in health centres. A cornerstone of the discipline is a continuous improvement based on avoiding medicine adverse events. Patients with chronic kidney disease (CRF) are at high risk for developing side effects and drug interactions. Inadequate drug prescribing in a patient with CRF may be toxic or ineffective. The elderly are particularly at risk. The chronic renal disease will alter glomerular blood flow, glomerular filtration rate, tubular secretion and reabsorption, as well as renal metabolism. This will cause changes in the absorption, bioavailability, protein binding, and volume of distribution and metabolism of the drugs. In the examination of empirical evidence of safety, from a toxicological point of view, research authorities have led them to conclude that there is no restriction on the use of gum arabic and did not raise any safety concerns [97]. The present clinical trial results are consistent with previous research.

\section{Conclusions}

In conclusion, today many scientific data are reinforcing the importance of diet for the establishment, composition, structure and functional activity of the human intestinal microbiota. Studies identifying mi- crobiota-health associations in humans provide evidence pointing to the role of diet in the pathogenesis of certain diseases through its effects on gut microbial communities. The modulation of dysbiotic microbiota with diet or the use of probiotics and prebiotics will surely help us prevent diseases such as obesity, renal stone, metabolic syndrome or cancer and, in general, many inflammatory processes. Arabic gum could be considered an important natural medicinal compound, because of its high therapeutic capabilities. Available evidence strongly suggests that gum arabic is an alternative therapeutic approach for patients with renal simple cysts and stones. This supports the idea to conduct a prospective observational study aimed to assess the efficacy and safety of treatment with gum arabic in patients with nephrolithiasis and renal cysts.

\section{Conflicts of Interest: The authors declare that they have no conflicts of interest.}

\section{Acknowledgements: This research would not have} been possible without the support of my family, professors, colleagues and friends. Special thanks to the dean of Dubai Pharmacy college professor Saeed Ahmed Khan, for allowing me to conduct my research. Thanks to my family, for encouraging me in all of my pursuits and inspiring me to follow my dreams. Finally, my thanks go to all the people who have supported me to complete the research work directly or indirectly.

\section{References}

1. Glassberg KI. Renal dysgenesis and cystic disease of the kidney. In: Walch PC, Retlik AB, Vaughan ED, Wein AJ. ed. Campbell Urology. Eighth Edition. Eisevier Science 2003.

2. Hepler AB. Solitary cysts of the kidney. Surg Gynecol Obstet. 1930; 50: $668-87$

3. Kern WF, Silva FG, Laszik ZG, Bane BL, Nadasdy T, Pitha JV. Atlas of Renal Pathology. WB Saunders Company, Philadelphia 1999: 235-246.

4. Walsh-Reitz MM, Toback FG. Kidney epithelial cell growth is stimulated by lowering extracellular potassium concentration. Am J Physiol. 1983; 244(5): C429-C432, doi: 10.1152/ajpcell.1983.244.5.C429, indexed in Pubmed: 6846530

5. Alpern RJ, Toto RD. Hypokalemic nephropathy-a clue to cystogenesis? NEnglJ Med. 1990; 322(6): 398-399, doi: 10.1056/NEJM199002083220609, indexed in Pubmed: 2300091

6. Torres VE, Young WF, Offord KP, et al. Association of hypokalemia, aldosteronism, and renal cysts. N Engl J Med. 1990; 322(6): 345-351 doi: 10.1056/NEJM199002083220601, indexed in Pubmed: 2405267.

7. Novello M, Catena C, Nadalini E, et al. Renal cysts and hypokalemia in primary aldosteronism: results of long-term follow-up after treatment. J Hypertens. 2007; 25(7): 1443-1450, doi: 10.1097/HJH.0b013e328126855b, indexed in Pubmed: 17563567.

8. Igarashi T, Shibuya K, Kamoshita S, et al. Renal cyst formation as a complication of primary distal renal tubular acidosis. Nephron. 1991; 59(1): 75-79, doi: 10.1159/000186522, indexed in Pubmed: 1944751

9. Vallés PG, Batlle D. Hypokalemic distal renal tubular acidosis. Adv Chronic Kidney Dis. 2018; 25(4): 303-320, doi: 10.1053/j. ackd.2018.05.003, indexed in Pubmed: 30139458

10. Vaisbich MH, Fujimura MD, Koch VH. Bartter syndrome: benefits and side effects of long-term treatment. Pediatr Nephrol. 2004; 19(8): 858863, doi: 10.1007/s00467-004-1527-8, indexed in Pubmed: 15206026. 
11. Watanabe T, Tajima T. Renal cysts and nephrocalcinosis in a patient with Bartter syndrome type III. Pediatr Nephrol. 2005; 20(5): 676-678, doi: 10.1007/s00467-004-1732-5, indexed in Pubmed: 15717167.

12. Moudgil A, Rodich G, Jordan SC, et al. Nephrocalcinosis and rena cysts associated with apparent mineralocorticoid excess syndrome. Pediatr Nephrol. 2000; 15(1-2): 60-62, doi: 10.1007/s004670000377 indexed in Pubmed: 11095013.

13. Ishikawa I. Uremic acquired renal cystic disease. Natural history and complications. Nephron. 1991; 58(3): 257-267, doi 10.1159/000186434, indexed in Pubmed: 1896090

14. Bisceglia M, Galliani CA, Senger $C$, et al. Renal cystic diseases: a review. Adv Anat Pathol. 2006; 13(1): 26-56, doi: 10.1097/01. pap.0000201831.77472.d3, indexed in Pubmed: 16462154

15. Peces R, Costero $O$. The spectrum of cystic kidney disease in adulthood: differential diagnosis and complications. Nefrologia. 2003; 23(3) 260-265, indexed in Pubmed: 12891942.

16. de Bruyn R, Gordon I. Imaging in cystic renal disease. Arch Dis Child. 2000; 83(5): 401-407, doi: 10.1136/adc.83.5.401, indexed in Pubmed: 11040148.

17. Marumo K, Horiguchi $\mathrm{Y}$, Nakagawa $\mathrm{K}$, et al. Incidence and growth pattern of simple cysts of the kidney in patients with asymptomatic microscopic hematuria. Int J Urol. 2003; 10(2): 63-67, doi 10.1046/j.1442-2042.2003.00577.x, indexed in Pubmed: 12588599.

18. Waltkins S, Avner E. Congenital and inherited disease. Renal Dysplasia Hypoplasia, and Miscellaneous Cystic Disorders. Polycystic Kidney Disease. In: Barrat M, Avner E, Harmon W. ed. Pediatric Nephrology Lippincott Williams \& Wilkins, 415-425 1998: 459-474.

19. de Bruyn R, Gordon I. Imaging in cystic renal disease. Arch Dis Child. 2000; 83(5): 401-407, doi: 10.1136/adc.83.5.401, indexed in Pubmed: 11040148.

20. Sakhaee K. Nephrolithiasis as a systemic disorder. Curr Opin Nephrol Hypertens. 2008; 17(3): 304-309, doi: 10.1097/MNH.0b013e3282f8b34d, indexed in Pubmed: 18408483.

21. Garcia Nieto V, Dublán García K, Luis Yanes MI. Are simple renal cysts another manifestation of prelithiasis in infancy? Nefrologia. 2010; 30(3): 337-341.

22. Williams PA, Idris O, Phillips GO. Structural analysis of gum from Acacia senegal (Gum Arabic). Cell and Developmental Biology of Arabinogalactan-Proteins. 2000: 241-251, doi: 10.1007/978-1-4615-4207-0_21.

23. Dashtdar M, Kardi K. Benefits of gum arabic, for a solitary kidney under adverse conditions: A case study. Chinese Medicine and Culture. 2018 1(2): 88-96, doi: 10.4103/cmac.cmac_22_18.

24. Ali NE, Kaddam LA, Alkarib SY, et al. Gum arabic (Acacia Senegal) augmented total antioxidant capacity and reduced C-reactive protein among haemodialysis patients in phase II trial. Int J Nephrol. 2020; 2020 7214673, doi: 10.1155/2020/7214673, indexed in Pubmed: 32328307

25. Nasir O, Artunc F, Saeed A, et al. Effects of gum arabic (Acacia senegal) on water and electrolyte balance in healthy mice. J Ren Nutr. 2008; 18(2): 230-238, doi: 10.1053/j.jrn.2007.08.004, indexed in Pubmed: 18267216

26. den Besten G, van Eunen K, Groen AK, et al. The role of short-chain fatty acids in the interplay between diet, gut microbiota, and host energy metabolism. J Lipid Res. 2013; 54(9): 2325-2340, doi: 10.1194/jr. R036012, indexed in Pubmed: 23821742.

27. Terpou A, Papadaki A, Lappa IK, et al. Probiotics in food systems: Significance and emerging strategies towards improved viability and delivery of enhanced beneficial value. Nutrients. 2019; 11(7), doi: 10.3390/nu11071591, indexed in Pubmed: 31337060

28. Klimesova K, Whittamore JM, Hatch M. Bifidobacterium animalis subsp. lactis decreases urinary oxalate excretion in a mouse model of primary hyperoxaluria. Urolithiasis. 2015; 43(2): 107-117, doi: 10.1007/s00240-014-0728-2, indexed in Pubmed: 25269440.

29. Jarrar AH, Stojanovska L, Apostolopoulos $\mathrm{V}$, et al The effect of gum arabic (Acacia Senegal) on cardiovascular risk factors and gastrointestinal symptoms in adults at Risk of Metabolic Syndrome: a randomized clinical trial. Nutrients. 2021:13(1), doi: 10.3390/nu13010194, indexed in Pubmed: 33435475

30. Ferguson $\mathrm{M}$, Jones $\mathrm{G}$. Production of short-chain fatty acids followingin vitro fermentation of saccharides, saccharide esters, fructo-oligosaccharides, starches, modified starches and non-starch polysaccharides. Journal of the Science of Food and Agriculture. 2000; 80(1) 166-170, doi: 10.1002/(sici)1097-0010(20000101)80:1<166::aid-jsfa512>3.0.co;2-k

31. Al Mosawi AJ. The use of acacia gum in end stage renal failure. J Trop Pediatr. 2007; 53(5): 362-365, doi: 10.1093/tropej/fmm033, indexed in Pubmed: 17517814

32. Al-Asmakh M, Sohail MU, Al-Jamal O, et al. The effects of gum acacia on the composition of the gut microbiome and plasma levels of short-chain fatty acids in a rat model of chronic kidney disease.
Front Pharmacol. 2020: 11: 569402, doi: 10.3389/fphar.2020.569402, indexed in Pubmed: 33628167

33. Leslie SW, Sajjad H, Nazzal L. Cystinuria. [Updated 2021 Apr 10]. In: StatPearls [Internet]. Treasure Island (FL): StatPearls Publishing; 2021. https://www.ncbi.nlm.nih.gov/books/NBK470527/.

34. Edrees B, Rasheed S. Urinary Stone Disease. In: Elzouki AY, Harfi HA, Nazer HM, Stapleton FB, Oh W, Whitley RJ. ed. Textbook of Clinical Pediatrics. Springer, Berlin,Heidelberg. 2012.

35. Dal Moro F, Mancini M, Tavolini IM, et al. Cellular and molecular gateways to urolithiasis: a new insight. Urol Int. 2005; 74(3): 193-197, doi: 10.1159/000083547, indexed in Pubmed: 15812202.

36. Alon $U$, Warady BA, Hellerstein S. Hypercalciuria in the frequency-dysuria syndrome of childhood. J Pediatr. 1990; 116(1): 103-105, doi: 10.1016/s0022-3476(05)81654-3, indexed in Pubmed: 2295948.

37. Vachvanichsanong P, Malagon M, Moore ES. Urinary tract infection in children associated with idiopathic hypercalciuria. Scand J Urol Nephrol. 2001; 35(2): 112-116, doi: 10.1080/003655901750170461, indexed in Pubmed: 11411652.

38. Garcia-Nieto V, Negrete-Pedraza F, Lopez-Garcia M, et al. Are simple renal cysts in childhood associated with kidney stones? Nephrourol Mon. 2012; 4(4): 596-598, doi: 10.5812/numonthly.2682, indexed in Pubmed: 23573497

39. Funck-Brentano JL, Vantelon J, Lopez-Alverez R. The progressive accidents of polycystic kidney disease: 154 personal observations. Presse Med. 1964; 30: 1583-1588.

40. Sakhaee K, Adams-Huet B, Moe OW, et al. Pathophysiologic basis for normouricosuric uric acid nephrolithiasis. Kidney Int. 2002; 62(3): 971-979, doi: 10.1046/j.1523-1755.2002.00508.x, indexed in Pubmed: 12164880.

41. So A, Thorens B. Uric acid transport and disease. J Clin Invest. 2010; 120(6): 1791-1799, doi: 10.1172/JCl42344, indexed in Pubmed: 20516647.

42. Compan V, Baroja-Mazo A, López-Castejón G, et al. Cell volume regulation modulates NLRP3 inflammasome activation. Immunity. 2012; 37(3): 487-500, doi: 10.1016/j.immuni.2012.06.013, indexed in Pubmed: 22981536

43. de Vries JE. Immunosuppressive and anti-inflammatory properties of interleukin 10. Ann Med. 1995; 27(5): 537-541, doi: 10.3109/07853899509002465, indexed in Pubmed: 8541028.

44. Moore KW, O'Garra A, de Waal Malefyt R, et al. Interleukin-10. Annu Rev Immunol. 1993; 11: 165-190, doi: 10.1146/annurev. iy.11.040193.001121, indexed in Pubmed: 8386517.

45. Dayer JM, Choy E. Therapeutic targets in rheumatoid arthritis: the interleukin-6 receptor. Rheumatology (Oxford). 2010; 49(1): 15-24, doi: 10.1093/rheumatology/kep329, indexed in Pubmed: 19854855

46. Rho $\mathrm{YH}$, Chung $\mathrm{CP}$, Oeser $\mathrm{A}$, et al. Inflammatory mediators and premature coronary atherosclerosis in rheumatoid arthritis. Arthritis Rheum. 2009; 61(11): 1580-1585, doi: 10.1002/art.25009, indexed in Pubmed: 19877084

47. Saxena A, Cronstein BN. Acute phase reactants and the concept of inflammation. In: Firestein GS, Budd RC, Gabriel SE, Mclnnes IB, O'Dell JR. ed. Textbook of Rheumatology. Vol 1. 9th. PA: Elsevier / Saunders, Philadelphia : 818-829.

48. Raison $\mathrm{CL}$, Borisov $\mathrm{AS}$, Majer $\mathrm{M}$, et al Activation of central nervous system inflammatory pathways by interferon-alpha: relationship to monoamines and depression. Biol Psychiatry. 2009; 65(4): 296-303, doi: 10.1016/j.biopsych.2008.08.010, indexed in Pubmed: 18801471.

49. Cerini C, Geider S, Dussol B, et al. Nucleation of calcium oxalate crystals by albumin: involvement in the prevention of stone formation. Kidney Int. 1999; 55(5): 1776-1786, doi: 10.1046/j.1523-1755.1999.00426x $x$ indexed in Pubmed: 10231440

50. Atmani F, Khan SR. Quantification of proteins extracted from calcium oxalate and calcium phosphate crystals induced in vitro in the urine of healthy controls and stone-forming patients. Urol Int. 2002; 68(1): 54-59, doi: 10.1159/000048418, indexed in Pubmed: 11803269.

51. Perl-Treves D, Addadi L. A structural approach to pathological crystallizations. Gout: the possible role of albumin in sodium urate crystallization. Proc R Soc Lond B Biol Sci. 1988; 235(1279): 145-159, doi: 10.1098/rspb.1988.0069, indexed in Pubmed: 2907144.

52. Sevillano AM, Gutierrez E, Morales E, et al. Multiple kidney cysts in thin basement membrane disease with proteinuria and kidney function impairment. Clin Kidney J. 2014; 7(3): 251-256, doi: 10.1093/ckj/sfu033, indexed in Pubmed: 25852885

53. Pizzino $G$, Irrera N, Cucinotta $M$, et al Oxidative stress: harms and benefits for human health. Oxid Med Cell Longev. 2017; 2017: 8416763, doi: 10.1155/2017/8416763, indexed in Pubmed: 28819546.

54. Bhattacharyya A, Chattopadhyay R, Mitra S, et al Oxidative stress: an essential factor in the pathogenesis of gastrointestinal mucosal diseases. Physiol Rev. 2014; 94(2): 329-354, doi: 10.1152/physrev.00040.2012, indexed in Pubmed: 24692350. 
55. Fedail J, Ahmed A, Musa $\mathrm{H}$, et al. Gum arabic improves semen quality and oxidative stress capacity in alloxan induced diabetes rats. Asian Pacific Journal of Reproduction. 2016; 5(5): 434-441, doi: 10.1016/j.apjr.2016.07.014

56. Flyvbjerg A, Denner L, Schrijvers BF, et al. Long-term renal effects of a neutralizing RAGE antibody in obese type 2 diabetic mice. Diabetes. 2004; 53(1): 166-172, doi: 10.2337/diabetes.53.1.166, indexed in Pubmed: 14693711.

57. Vasavada N, Agarwal R. Role of oxidative stress in diabetic nephropathy. Adv Chronic Kidney Dis. 2005; 12(2): 146-154, doi: 10.1053/j. ackd.2005.01.001, indexed in Pubmed: 15822050.

58. Lobo V, Patil A, Phatak A, et al. Free radicals, antioxidants and functiona foods: Impact on human health. Pharmacogn Rev. 2010; 4(8): 118-126, doi: 10.4103/0973-7847.70902, indexed in Pubmed: 22228951.

59. Al-Majed AA, Abd-Allah ARA, Al-Rikabi AC, et al. Effect of oral administration of Arabic gum on cisplatin-induced nephrotoxicity in rats. J Biochem Mol Toxicol. 2003; 17(3): 146-153, doi: 10.1002/jbt.10072, indexed in Pubmed: 12815610.

60. Abd-Allah ARA, Al-Majed AA, Mostafa AM, et al. Protective effect of arabic gum against cardiotoxicity induced by doxorubicin in mice: a possible mechanism of protection. J Biochem Mol Toxicol. 2002; 16(5): 254-259, doi: 10.1002/jbt.10046, indexed in Pubmed: 12439867.

61. Trommer $\mathrm{H}$, Neubert $\mathrm{RHH}$. The examination of polysaccharides as potential antioxidative compounds for topical administration using a lipid model system. Int J Pharm. 2005; 298(1): 153-163, doi: 10.1016/j. ijpharm.2005.04.024, indexed in Pubmed: 15955644.

62. Park EY, Murakami H, Matsumura Y. Effects of the addition of amino acids and peptides on lipid oxidation in a powdery model system. J Agric Food Chem. 2005; 53(21): 8334-8341, doi: 10.1021/jf058063u, indexed in Pubmed: 16218685.

63. Ali BH, Al-Husseni I, Beegam S, et al. Effect of gum arabic on oxidative stress and inflammation in adenine-induced chronic renal failure in rats. PLoS One. 2013; 8(2): e55242, doi: 10.1371/journal. pone.0055242, indexed in Pubmed: 23383316

64. Caravaca F, Villa J, García de Vinuesa E, et al. Relationship between serum phosphorus and the progression of advanced chronic kidney disease. Nefrologia. 2011; 31(6): 707-715, doi: 10.3265/Nefrologia. pre2011.Sep.11089, indexed in Pubmed: 22130287.

65. Kestenbaum B, Sampson JN, Rudser KD, et al. Serum phosphate levels and mortality risk among people with chronic kidney disease. J Am Soc Nephrol. 2005; 16(2): 520-528, doi: 10.1681/ASN.2004070602, indexed in Pubmed: 15615819.

66. Chue CD, Townend JN, Moody WE, et al. Serum phosphate but not pulse wave velocity predicts decline in renal function in patients with early chronic kidney disease. Nephrol Dial Transplant. 2011; 26(8) 2576-2582, doi: 10.1093/ndt/gfq787, indexed in Pubmed: 21248296.

67. Marchais SJ, Metivier F, Guerin AP, et al. Association of hyperphosphataemia with haemodynamic disturbances in end-stage renal disease. Nephrol Dial Transplant. 1999; 14(9): 2178-2183, doi: 10.1093/ndt/14.9.2178, indexed in Pubmed: 10489228

68. Sekiguchi S, Suzuki A, Asano S, et al. Phosphate overload induces podocyte injury via type III Na-dependent phosphate transporter. Am J Physiol Renal Physiol. 2011; 300(4): F848-F856, doi: 10.1152/ajprenal.00334.2010, indexed in Pubmed: 21307129

69. Halbesma N, Kuiken DS, Brantsma AH, et al. Macroalbuminuria is a better risk marker than low estimated GFR to identify individuals at risk for accelerated GFR loss in population screening. J Am Soc Nephrol. 2006; 17(9): 2582-2590, doi: 10.1681/ASN.2005121352, indexed in Pubmed: 16899519.

70. van der Velde M, Halbesma N, de Charro FT, et al. Screening for albuminuria identifies individuals at increased renal risk. J Am Soc Nephrol. 2009; 20(4): 852-862, doi: 10.1681/ASN.2008060655, indexed in Pubmed: 19211710.

71. Fabris A, Ferraro PM, Comellato $G$, et al. The relationship between calcium kidney stones, arterial stiffness and bone density: unraveling the stone-bone-vessel liaison. J Nephrol. 2015; 28(5): 549-555, doi: 10.1007/s40620-014-0146-0, indexed in Pubmed: 25266216.

72. Shavit L, Girfoglio D, Vijay V, et al. Vascular calcification and bone mineral density in recurrent kidney stone formers. Clin J Am Soc Nephrol. 2015; 10(2): 278-285, doi: 10.2215/CJN.06030614, indexed in Pubmed: 25635036.

73. Rodgers A, Barbour L, Pougnet B, et al. Urinary element concentrations in kidney stone formers and normal controls: the weekend effect $J$ Trace Elem Electrolytes Health Dis. 1994; 8(2): 87-91, indexed in Pubmed: 7881282

74. Komleh K, Hada P Pendse AK et al. Zinc copper and manganese in serum, urine and stones. Int Urol Nephrol. 1990; 22(2): 113-118, doi: 10.1007/BF02549826, indexed in Pubmed: 2354889.
75. Lorenzo V. Chronic renal failure outpatient clinic. A 12 years' experience. Nefrologia. 2007; 27(4): 425-433, indexed in Pubmed: 17944579.

76. Ruggenenti P, Perna A, Remuzzi G, et al. GISEN Group Investigators. Retarding progression of chronic renal disease: the neglected issue of residual proteinuria. Kidney Int. 2003; 63(6): 2254-2261, doi: 10.1046/j.1523-1755.2003.00033.x, indexed in Pubmed: 12753315.

77. Taal MW, Brenner BM. Predicting initiation and progression of chronic kidney disease: Developing renal risk scores. Kidney Int. 2006; 70(10): 1694-1705, doi: 10.1038/sj.ki.5001794, indexed in Pubmed: 16969387.

78. Abbate M, Zoja C, Remuzzi G. How does proteinuria cause progressive renal damage? J Am Soc Nephrol. 2006; 17(11): 2974-2984, doi: 10.1681/ASN.2006040377, indexed in Pubmed: 17035611

79. Jafar TH, Stark PC, Schmid CH, et al. AIPRD Study Group. Angiotensin-Converting Enzymne Inhibition and Progression of Renal Disease. Proteinuria as a modifiable risk factor for the progression of non-diabetic renal disease. Kidney Int. 2001; 60(3): 1131-1140, doi: 10.1046/j.1523-1755.2001.0600031131.x, indexed in Pubmed: 11532109.

80. Ruggenenti P, Perna A, Mosconi L, et al. Urinary protein excretion rate is the best independent predictor of ESRF in non-diabetic proteinuric chronic nephropathies. "Gruppo Italiano di Studi Epidemiologici in Nefrologia" (GISEN). Kidney Int. 1998; 53(5): 1209-1216, doi: 10.1046/j.1523-1755.1998.00874.x, indexed in Pubmed: 9573535.

81. McClellan WM, Flanders WD. Risk factors for progressive chronic kidney disease. J Am Soc Nephrol. 2003; 14(7 Suppl 2): S65-S70, doi: 10.1097/01.asn.0000070147.10399.9e, indexed in Pubmed: 12819305.

82. Cirillo M, Laurenzi M, Panarelli W, et al. Urinary sodium to potassium ratio and urinary stone disease. Kidney International. 1994; 46(4): 1133-1139, doi: 10.1038/ki.1994.376

83. Kleeman CR, Bohannan J, Bernstein D, et al. Effect of variations in sodium intake on calcium excretion in normal humans. Proc Soc Exp Biol Med. 1964; 115: 29-32, indexed in Pubmed: 14117460.

84. McCarron DA, Rankin LI, Bennett WM, et al. Urinary calcium excretion at extremes of sodium intake in normal man. Am J Nephrol. 1981; 1(2): 84-90, doi: 10.1159/000166496, indexed in Pubmed: 6295160.

85. Muldowney FP, Freaney R, Moloney MF. Importance of dietary sodium in the hypercalciuria syndrome. Kidney Int. 1982; 22(3): 292-296, doi: 10.1038/ki.1982.168, indexed in Pubmed: 7176331.

86. Sabto J, Powell MJ, Breidahl MJ, et al. Influence of urinary sodium on calcium excretion in normal individuals. A redefinition of hypercalciuria. Med J Aust. 1984; 140(6): 354-356, indexed in Pubmed: 6700493.

87. Shortt C, Flynn A. Sodium-calcium inter-relationships with specific reference to osteoporosis. Nutr Res Rev. 1990; 3(1): 101-115, doi: 10.1079/NRR19900008, indexed in Pubmed: 19094334

88. Blackwood AM, Cappuccio FP, Sagnella GA, et al. Epidemiology of blood pressure and urinary calcium excretion:importance of ethnic origin and diet. J Hum Hypert. 1999; 13: 892-3.

89. Hall WD, Pettinger M, Oberman A, et al. Risk factors for kidney stones in older women in the southern United States. Am J Med Sci. 2001 322(1): 12-18, doi: 10.1097/00000441-200107000-00003, indexed in Pubmed: 11465241.

90. Kohri K, Garside J, Blacklock NJ. The role of magnesium in calcium oxalate urolithiasis. Br J Urol. 1988; 61(2): 107-115, doi: 10.1111/j.1464-410x.1988.tb05057.x, indexed in Pubmed: 3349276.

91. Zuckerman JM, Assimos DG. Hypocitraturia: pathophysiology and medical management. Rev Urol. 2009; 11(3): 134-144, indexed in Pubmed: 19918339

92. Marangella M, Vitale $\mathrm{C}$, Bagnis $\mathrm{C}$, et al. Crystallization inhibitors in the pathophysiology and treatment of nephrolithiasis. Urol Int. 2004; 72 Suppl 1(2): 6-10, doi: 10.1159/000076583, indexed in Pubmed: 15133325

93. Baumann WC, Casella R. Prevention of calcium nephrolithiasis: the influence of diuresis on calcium oxalate crystallization in urine. Adv Prev Med. 2019; 2019: 3234867, indexed in Pubmed 31016047.

94. Shenoy C. Hypocitraturia despite potassium citrate tablet supplementation. MedGenMed. 2006; 8(3): 8, indexed in Pubmed: 17406150.

95. Wang $\mathrm{YH}$, Grenabo L, Hedelin $\mathrm{H}$, et al. Citrate and urease-induced crystallization in synthetic and human urine. Urol Res. 1993; 21(2): 109-115, doi: 10.1007/BF01788828, indexed in Pubmed: 8503146.

96. Krieger NS, Asplin JR, Frick KK, et al. Effect of potassium citrate on calcium phosphate stones in a model of hypercalciuria. J Am Soc Nephrol. 2015; 26(12): 3001-3008, doi: 10.1681/ASN.2014121223, indexed in Pubmed: 25855777

97. Anderson DM. Evidence for the safety of gum arabic (Acacia senegal (L.) Willd.) as a food additive--a brief review. Food Addit Contam. 1986; 3(3): 225-230, doi: 10.1080/02652038609373584, indexed in Pubmed: 3743831 